\title{
Tratamento lexicográfico de dados geolinguísticos: discussões a partir da elaboração do Vocabulário dialetal do Centro-Oeste
}

\section{Lexicographic treatment of geolinguistic data: discussions from the preparation of the Dialetal vocabulary of Midwest region}

\begin{abstract}
Resumo: Haja vista a importância dos dicionários para o conhecimento das línguas, uma vez que são fonte de consulta por documentarem palavras em uso por uma comunidade e as munirem de diversas informações linguísticas e extralinguísticas, este texto discute a interdisciplinaridade da Lexicografia, tendo como objetivo refletir sobre as interfaces entre Lexicografia, Dialetologia e Geolinguística, recuperando parte da história dessas disciplinas e também alguns de seus produtos, como o Vocabulário dialetal do Centro-Oeste (COSTA, 2018). Esperase assim que se fomentem discussões sobre a necessidade de o fazer lexicográfico congregar, além de preceitos teóricos da Lexicografia, o conhecimento de outros saberes, como os de estudos dialetológicos e geolinguísticos.
\end{abstract}

Palavras-chave: Lexicografia. Dialetologia e Geolinguística. Interfaces. Vocabulário Dialetal do Centro-Oeste.

\begin{abstract}
In view of the importance of dictionaries for the language knowledge, since they are a source of consultation for documenting words in use by a community and providing them with diverse linguistic and extralinguistic information, this text discusses the interdisciplinarity of Lexicography, aiming to reflect on the interfaces between Lexicography, Dialectology and Geolinguistics, recovering part of the history of these disciplines and also some of its products, such as the Vocabulário dialetal do Centro-Oeste (COSTA, 2018). It is hoped, therefore, that discussions are promoted on the need of lexicographic make bring together, in addition to theoretical precepts of Lexicography, other knowledges, such as those of dialectical and geolinguistic studies.
\end{abstract}

Keywords: Lexicography. Dialectology and Geolinguistics. Interfaces. Vocabulário Dialetal do Centro-Oeste.

Apenas com o aproveitamento dos atlas linguísticos poderá sair nossa lexicografia dos limites que a comprimem. Cada época cientifica exige novos métodos e não podemos continuar com uma

*Professora Doutora - Universidade Federal do Mato Grosso do Sul, Aquidauana, Mato Grosso do Sul, Brasil. Email: danielassilva@hotmail.com. 
lexicografia que ainda não tenha recebido o alvorecer do século XX. ${ }^{1}$

(ALVAR, 1980, p. 73)

\section{INTRODUÇÃO}

Alvar (1980), em seu texto "Atlas lingüístico y diccionarios”, reflete sobre uma questão muito cara à Lexicografia e profícua a este texto: a interdisciplinaridade. Isso porque a elaboração e mesmo o estudo de dicionários exige o conhecimento sobre diversas áreas, como Semântica, Lexicologia, Morfologia etc. e, no que tange à argumentação que ora se apresenta, também relações com atlas linguísticos e novos métodos, tema do linguista espanhol, aqui tratadas a partir da interface dessa disciplina com a Dialetologia, a Geolinguística, a Linguística de Corpus e a Linguística Computacional pela discussão de um trabalho que buscou a aplicação desse encontro teórico: o Vocabulário dialetal do Centro-Oeste (COSTA, 2018).

A Lexicografia surgiu com a Renascença, período que marcou o fim do século XIV e o final do século XVI e assinalou a transição entre as Idades Média e Moderna. Antes, porém, desde a Antiguidade, sumérios e acádios já haviam iniciado a produção de coleções de signos, uma espécie de dicionário monolíngue, e glossários bilíngues datados de 2.600 a.C. (FERNÁNDEZ-SEVILLA, 1974).

Também os estudos dialetológicos se desenvolveram antes de a Dialetologia se estabelecer como campo teórico. O interesse do homem pela diversidade entre as línguas foi despertado desde muito antes, esta entendida inicialmente, inclusive, como uma punição divina ${ }^{2}$. Cardoso (2010), citando o livro bíblico dos Juízes, destaca que o reconhecimento dos diversos falares servia para distinguir a origem das pessoas, como no caso de, naqueles tempos, a forma de pronunciar chibólet já identificava os efraimitas dentre os galaaditas:

Galaad ocupou os vaus do Jordão, e cada vez que um fugitivo de Efraim queria passar, perguntavam-lhes: És tu efraimita? Ele respondia: Não. Pois bem, diziam eles então, dize: Chibólet, não podendo pronunciar corretamente. Prendiam-no logo e o degolavam junto dos vaus do Jordão. (BÍBLIA SAGRADA, [s.d.] apud CARDOSO, 2010, p. 28) (grifo nosso)

Já como um primeiro registro de variação regional da língua espanhola, Camacho Niño (2010, p. 64) menciona “[...] a precoce inclusão da voz canoa no Vocabulario de

\footnotetext{
${ }^{1}$ Do original: "Solo con el aprovechamiento de los atlas lingüísticos podrà salir nuestra lexicografía de los límites que la constriñen. Cada época científica exige nuevos métodos y no podemos continuar con una lexicografía que no há saludado todavia los albores del siglo XX" (tradução nossa).

${ }^{2}$ No livro bíblico do Gênesis, relata-se o caso da Torre de Babel, quando Jeová, o Deus hebraico, irritouse com os descendentes de Noé que, após o dilúvio, tentaram construir uma torre para chegarem ao céu, tornarem-se famosos e não se dispersarem pela terra. A punição foi proferida: "[...] vamos descer e confundir a língua deles, para que um não entenda a língua do outro” (BÍBLIA SAGRADA, 1990, p. 22).
} 
romance en latín (1495?) de Antonio de Nebrija"3, palavra que, segundo Alvar Ezquerra (1992, p. 200), seria conhecida pela Península Ibérica apenas após o retorno de Cristóvão Colombo de sua primeira viagem como descobridor em 1493.

Porém o construto da Lexicografia passou a mais fortemente se servir dos estudos da Dialetologia, ambas já desenvolvidas em termos teóricos, em meados do século XIX. Em 1836, por exemplo, Esteban Pichardo publicou o Diccionario de voces cubanas, cuja importância dá-se como fonte lexicográfica e também como um documento da Cuba do século XIX.

Quanto ao uso de atlas linguísticos em produções lexicográficas - sendo os atlas trabalhos dialetológicos elaborados a partir da Geografia Linguística, ou Geolinguística, o método da Dialetologia para o mapeamento de dados coletados - e retomando as palavras de Alvar (1980), o Brasil teve sua primeira publicação no acender de luzes do século XXI: em 2000, Cardoso e Ferreira publicaram O léxico rural: glossário e comentários, cujo corpus advinha do Atlas prévio dos falares baianos - AFPB (1963) e do Atlas linguístico do Sergipe ALS (1987).

Como já mencionado, este trabalho também apresentará um resultado dessa interface: o Vocabulário dialetal do Centro-Oeste, produto de tese de doutorado defendida na Universidade Estadual de Londrina em 2018 sob o título "Vocabulário dialetal do CentroOeste: interfaces entre a Lexicografia e a Dialetologia" (COSTA, 2018), elaborado também com o auxílio da Linguística de Corpus e da Linguística Computacional.

\section{REVISÃO DE LITERATURA}

Os dicionários, desde seu início, buscavam ser “[...] uma espécie de tentativa de descrição do léxico de uma língua” (BIDERMAN, 2001, p. 131), objetivo que norteava e continua a orientar o fazer lexicográfico. Porém apenas com o desenvolvimento paulatino de produções que descreviam de alguma forma o léxico é que começaram a ser empreendidos estudos que, por sua vez, produziam obras com maior maturidade científica, pois a Lexicografia "[...] nasceu como uma tradição textual e não como um produto de uma organização intelectual prévia da matéria dos dicionários” (LARA, 2004, p. 148).

Em relação a esse desenvolvimento, passaram a emergir, na década de 1940, estudos sobre a frequência das palavras na elaboração de materiais de ensino de língua estrangeira, o que pode ser considerado um embrião de uma Lexicografia teórica. Nessa década, publicou-se um dos primeiros trabalhos da área, de autoria do russo L. V. Šcerba, “[...] com uma teoria geral da lexicografia" (HAENSCH; OMEÑACA, 2004, p. 35). Na década de 1960, na França, produziram-se também Les vocabulaires français (Robert - Leon Wagner) e a tese de Bernard Quemada (Les diccionaires du français moderne, 1539-1863), além

\footnotetext{
${ }^{3}$ Do original: “[...] La temprana inclusión de la voz canoa en el Vocabulario de romance en latín (¿1495?) de Antonio de Nebrija” (tradução nossa).

${ }^{4}$ Do original: “[...] Con una teoría general de la lexicografía” (tradução nossa).
} 
do Étude sur leur histoire, leus types el leurs méthodes (1968) e La histoire des diccionaires français (1968), ambos de Georges Matoré (AZORÍN FERNÁNDEZ, 2003, p. 44).

Os anos de 1970 deram início, na Espanha, a publicações voltadas a uma teoria lexicográfica, com obras de “[...] Manuel Seco (1971), Julio Fernández-Sevilla (1974), Manuel Alvar Ezquerra (1976), Germán Colón (1979) y Alvaro Porto-Dapena ([já em] 1980)" (HAENSCH; OMEÑACA, 2004, p. 41).

Assim, ao lado da já existente Lexicografia prática, o ofício de fazer dicionários, começou a surgir uma Lexicografia teórica, também chamada de Metalexicografia.

A lexicografia teórica ou metalexicografia se constitui junto à lexicografia prática - o caráter eminentemente prático que possui a lexicografia está fora de toda dúvida - como um âmbito científico novo que circunscreve um objeto múltiplo, já que sua finalidade não é apenas um dicionário mas também, e fundamentalmente, a investigação que trata do dicionário ${ }^{5}$. (ANGLADA ARBOIX, 1991, p. 7)

A par do desenvolvimento da Lexicografia em âmbito geral, também avançavam em termos qualitativos e quantitativos os estudos lexicográficos com vistas à diversidade linguística, aqueles voltados à Lexicografia Dialetal, o "[...] ramo da lexicografia que se ocupa da redação de dicionários diferenciais da variedade diatópica de uma língua, isto é, da formalização lexicográfica das variedades espaciais de uma língua em seu sentido mais amplo" (AHUMADA, 2000, p. 14). Para Ahumada Lara (2007), a Lexicografia Regional nasceu com os glossários, amparo para o entendimento de obras literárias, de caráter histórico ou geográfico.

Nas fontes bibliográficas consultadas sobre o tema, nota-se o uso de duas designações: Lexicografia Regional e Lexicografia Dialetal. Ambas remetem aos conceitos de léxico regional e dialetal, respectivamente. Para Isquerdo (2012, p. 116), o léxico dialetal é formado pelas "[...] variantes lexicais que identificam áreas demarcadas geolinguisticamente [e] que evidenciam de forma bastante particular o vocabulário de uma comunidade de falantes". Já o léxico regional pode ser "[...] entendido genericamente como a norma lexical veiculada por habitantes circunscritos a áreas geográficas de diferentes dimensões” (ISQUERDO, 2012, p. 116).

Em outras palavras, o léxico regional contempla a norma lexical mais geral, talvez até de maneira inespecífica, considerando as diferentes normas linguísticas ativas no falar de comunidades que habitam diversas áreas geográficas, tanto países distintos como regiões diferentes no mesmo país, ou ainda áreas menores, como a diversidade entre a fala de cidades vizinhas.

Já o léxico dialetal relaciona-se diretamente com as pesquisas dialetológicas e geolinguísticas, que revelam áreas dialetais demarcadas, estas que nem sempre (ou quase nunca) coincidem com os limites político-geográficos das regiões consideradas, revelando-se como termo mais científico que a primeira designação.

\footnotetext{
${ }^{5}$ Do original: "La Lexicografía teórica o metalexicografía se constituye junto a la lexicografía práctica - el carácter eminentemente práctico que posee la lexicografía está fuera de toda duda - como un ámbito científico nuevo que circunscribe un objeto múltiple ya que su finalidad no és solo un diccionario, sino también y fundamentalmente, la investigación que trata del diccionario" (tradução nossa).
} 
Aqui se vê a convergência entre a Lexicografia e a Dialetologia, uma vez que, desde a denominação escolhida para nos referirmos aos trabalhos lexicográficos que versam sobre as variedades linguísticas, encontramos a interface entre as disciplinas.

Sobre o início da Dialetologia como o "[...] ramo dos estudos da ciência da linguagem que se ocupa da variação e da diversidade de usos" (CARDOSO, 2008, p. 16), Chambers e Trudgill (1994) citam o trabalho de Wenker (1876), que entrevistou por correspondência 50.000 professores alemães pedindo-lhes que escrevessem certas frases em dialetos locais. A partir de alguns problemas identificados na pesquisa do alemão, como a forma indireta com que coletou seus dados, métodos dialetológicos e geolinguísticos foram sendo apurados, dando bases para novas pesquisas com maior rigor metodológico, caráter científico que muito se enriqueceu com o fato de, nesse mesmo século (em 1881), a França, impulsionada pelos estudos dos patois e pelo particular interesse de Jules Gilliéron, ter inserido a Dialetologia no currículo regular da École Pratique des Hautes Études, de Paris (BRANDÃO, 1991, p. 8).

Já no nascer do século XX, resultado ainda do trabalho do século anterior, a França lançou seu Atlas linguistique de la France (publicado entre 1902 e 1910), de Gilliéron e Edmond Edmont, este que realizava a coleta de dados e aquele que os recebia e compilava. Apesar das críticas recebidas por esse trabalho, pautadas especialmente no fato de Edmont, responsável pelos inquéritos, não ser um linguista, "[...] a pesquisa desses dialetólogos é considerada um marco para a Dialetologia e fonte de investigação para estudos que os sucederam" (CHAMBERS; TRUDGILL, 1994, p. 41).

Desde, pois, os trabalhos de Gilliéron, a Dialetologia se vale do método fornecido pela Geolinguística ou Geografia Linguística, que, “[...] como a Dialetologia, estuda a variação da língua, mas a estuda no espaço e a reflete sobre mapas" (GARCÍA MOUTON, 2009, p. 63). Porém a Geolinguística contemporânea considera também outros fatores para a descrição da língua, como atestam Mota e Cardoso (2006):

\begin{abstract}
$\mathrm{Na}$ geolinguística pluridimensional contemporânea, soma-se ao parâmetro diatópico, prioritário em trabalhos dessa natureza, o interesse por outros tipos de variação, como a diagenérica [variação entre os gêneros/sexos masculino e feminino], a diastrática [variantes sociais], a diageracional [considerando-se a idade dos falantes], entre outras. (MOTA; CARDOSO, 2006, p. 22)
\end{abstract}

A Geografia Linguística pode então ser entendida como o método dialetológico para o mapeamento de dados coletados ${ }^{7}$, uma vez que registra as informações por meio de cartas/mapas linguísticos que fornecem recursos práticos para a análise do fenômeno linguístico documentado. Seu objetivo é, assim,

\footnotetext{
${ }^{6}$ Do original: “[...] Como la Dialectologia, estudia la variación de la lengua, pero la estudia en el espacio, e la refleja sobre mapas" (tradução nossa).

${ }^{7}$ Há outras vertentes teóricas que consideram a Geolinguística como campo de investigação autônomo e não como método da Dialetologia. Para conhecer melhor essa posição teórica, recomenda-se a leitura, dentre outros textos, de Romano (2013).
} 
o registro em mapas especiais de um número relativamente elevado de formas linguísticas (fônicas, lexicais ou gramaticais) comprovadas mediante pesquisa direta e unitária numa rede de pontos de um determinado território, ou que, pelo menos, têm em conta a distribuição das formas no espaço geográfico correspondente à língua, às línguas, aos dialetos ou aos falares estudados. (COSERIU, 1982, p. 79)

Considerando, pois, a Dialetologia e a Geolinguística, vê-se a importância de ambos os ramos linguísticos para o fazer lexicográfico, uma vez que favorecem o estudo dos dialetos em uso em dadas comunidades e, consequentemente, o registro do léxico dialetal (ou de marcas diatópicas de determinadas unidades lexicais) em dicionários. E ambas contribuem sobremaneira para o avanço da Lexicografia moderna no que diz respeito, dentre outras coisas, à fiabilidade de suas produções em relação à norma que documentam. Sousa Fernández (2010), sobre o tema, argumenta que,

Entre as disciplinas linguísticas que mais proveito têm tirado dos atlas linguísticos, figura a lexicografia. Os materiais que oferecem os atlas se convertem amiúde em uma valiosa fonte de informações para dicionários gerais, dicionários dialetais e dicionários etimológicos ${ }^{8}$. (SOUSA FERNÁNDEZ, 2010, p. 241)

Isso porque os atlas possibilitam à Lexicografia desfazer-se das amarras que lhe eram impostas pela exclusividade de fontes anteriores à cartografia geolinguística, que se restringiam a documentos, por vezes antigos, ou que não revelavam, de fato, a língua em uso. E sobretudo a Lexicografia Dialetal ganhou impulso com o uso dos atlas como corpus, haja vista que se pode firmar em dados coletados segundo parâmetros metodológicos que garantem a documentação do uso da língua em diferentes contextos geográficos, podendo descrever com mais propriedade as variedades linguísticas vivas em determinado território.

Assim sendo, os atlas linguísticos proporcionam à Lexicografia e a todos os seus consulentes informações vivas e comparáveis a respeito do uso de uma língua em um espaço geográfico.

Como exemplo de tratamento lexicográfico de dados geolinguísticos, este texto já mencionou a publicação de Cardoso e Ferreira (2000). De grande domínio, pode-se informar o projeto Dicionário Dialetal Brasileiro (DDB), que também se vale de dados geolinguísticos, no caso de dados do Projeto Atlas Linguístico do Brasil. "O DDB objetiva conjugar de forma abrangente língua e cultura, de forma a permitir o conhecimento mais abrangente possível da relação dialetal que se estabelece, através do léxico, nas comunidades que o utilizam" (MACHADO FILHO; NEIVA, 2015, p. 43).

Vê-se assim que as produções lexicográficas têm buscado em fontes geolinguísticas e dialetais dados consistentes para sua elaboração. Contudo esse tratamento exige ainda do lexicógrafo novos métodos, como já anunciara Alvar (1980) na epígrafe deste artigo,

\footnotetext{
${ }^{8}$ Do original: "Entre las disciplinas lingüísticas que más provecho han sacado de los atlas lingüísticos figura la lexicografía. Los materiales que ofrecem los atlas se convierten a menudo en una valiosa fuente de información para diccionarios generales, diccionarios dialectales y diccionarios etimológicos" (tradução nossa).
} 
posto que o volume de informações fornecidas pelos atlas linguísticos requer a organização e a análise de corpora não raras vezes muito extensos.

Nesse sentido, para a manipulação lexicográfica dos resultados de trabalhos geolinguísticos, a Lexicografia se vale de novas relações interdisciplinares, sendo auxiliada pela Linguística de Corpus e pela Linguística Computacional, por exemplo.

De acordo com Berber Sardinha (2000), a Linguística de Corpus

ocupa-se da coleta e exploração de corpora ou conjunto de dados linguísticos textuais que foram coletados criteriosamente com o propósito de servirem para a pesquisa de uma língua ou variedade linguística. Como tal, dedica-se à exploração da linguagem através de evidências empíricas, extraídas por meio de computador. (BERBER SARDINHA, 2000, p. 325)

Os corpora há muito fazem parte do fazer lexicográfico, mas os eletrônicos, especialmente, passaram a contribuir para ele a partir do maior desenvolvimento da Linguística de Corpus e atendem à Lexicografia de várias formas. Além das já citadas confiabilidade e comparabilidade, possibilitam descobrir "[...] a maior lista de palavras de uma língua com suas respectivas freqüências” (DURAN, 2008, p. 1793), além de auxiliarem o lexicógrafo na seleção de exemplos que integrarão os verbetes. Duran (2008) descreve diversos outros benefícios com o uso da abordagem baseada em corpora pela Lexicografia, que ela classifica entre diretos e indiretos:

Os benefícios indiretos impactam as decisões acerca do tipo de dicionário a ser produzido: a quem se destina, o que deve conter, como deve ser organizado etc. [...] Já os benefícios diretos [são] representados pelas informações a respeito do comportamento do léxico, suas propriedades combinatórias, suas diversas realizações de sentido, suas ocorrências nos diversos registros da língua. (DURAN, 2008, p. 1794)

Além disso, a modernização na produção de dicionários tende a apresentar ainda mais resultados advindos de corpora eletrônicos, haja vista as obras lexicográficas eletrônicas que têm se desenvolvido com destaque a partir dos anos 2000. Isso porque a questão da seleção de entradas não se submete ao quesito espaço de publicação como nos dicionários impressos. Dessa forma, os resultados poderão ser apresentados em maior número nas obras eletrônicas, respondendo a críticas comuns aos trabalhos lexicográficos que versam especialmente sobre a omissão de informações existentes nos corpora pesquisados.

Porém, para isso, a Informática também se estabelece como recurso indispensável, posto que oferece ferramentas específicas que auxiliam e mesmo possibilitam ao lexicógrafo trabalhar com vastos volumes de informações e procedimentos estatísticos para as análises e, de acordo com cada objetivo a ser considerado nas pesquisas, novos processos e utilitários para os estudos. Esse é o campo de atuação da Linguística Computacional.

Muitas vezes tomada como uma subsidiária da Linguística de Corpus, a Linguística Computacional tem suas áreas de abrangência muito mais amplas do que apenas atender à compilação e à organização de corpora. 
A linguística computacional constitui um campo científico de caráter interdisciplinar, vinculado à linguística e à informática, cujo fim fundamental é a elaboração de modelos computacionais que reproduzam distintos aspectos da linguagem humana e que facilitem o tratamento informatizado das línguas?. (PÉREZ HERNÁNDEZ; MORENO ORTIZ, 2009, p. 68)

Ela também é conhecida com outras designações, como, por exemplo, a mais mencionada delas, Processamento Automático de Línguas Naturais (PLN - sigla derivada do inglês, origem do nome), além de Linguística Informática e Engenharia Linguística, nomes menos usuais.

No ramo da Informática, a Linguística Computacional é subdisciplina da Inteligência Artificial e, na Linguística, a depender de seu enfoque, relaciona-se à Linguística Teórica ou à Linguística Aplicada. Isso porque é composta por três principais linhas de investigação: a Linguística Computacional Teórica; a Linguística Computacional Aplicada; e a Informática Aplicada à Linguística.

A par da Linguística Computacional Teórica, que elabora modelos linguísticos formais, aplicando-os a diferentes níveis de descrição linguística e comprovando, por meio da informática, a correspondência entre eles e suas hipóteses, o viés mais conhecido e exigido pelas pesquisas linguísticas é da Linguística Computacional Aplicada, "[...] que se concentra, grosso modo, no desenvolvimento de sistemas computacionais capazes de gerenciar, compreender, produzir e traduzir enunciados orais e escritos em linguagem natural, para o que desenvolve aplicações informáticas"10 (PÉREZ HERNÁNDEZ; MORENO ORTIZ, 2009, p. 68).

Frente ao exposto, reconhece-se o caráter interdisciplinar da Lexicografia, que exige de seus pesquisadores outros conhecimentos para além de seu próprio referencial teórico para a elaboração de obras lexicográficas ou mesmo para o estudo de dicionários sob diferentes perspectivas, assim como preleciona Alvar (1980).

Nessa seara, depois de apresentar os princípios gerais das relações interdisciplinares entre a Lexicografia e a Dialetologia, a Geolinguística, a Linguística de Corpus e a Linguística Computacional, como previsto como objetivo inicial deste texto, sua continuidade apresentará essa interface aplicada à elaboração de uma obra lexicográfica: o Vocabulário dialetal do Centro-Oeste.

\section{VOCABULÁRIO DIALETAL DO CENTRO-OESTE: INTERFACES ENTRE LEXICOGRAFIA E DIALETOLOGIA}

\footnotetext{
${ }^{9}$ Do original: "La lingüística computacional constituye un campo científico de carácter interdisciplinar, vinculado a la lingüística y a la informática, cuyo fin fundamental es la elaboración de modelos computacionales que reproduzan distintos aspectos del linguaje humano y que faciliten el tratamento informatizado de las lenguas" (tradução nossa).

${ }^{10}$ Do original: "[...] Que se centra, a grandes rasgos, en el diseño de sistemas informáticos capaces de gestionar, comprender, producir y traducir enunciados orales y escritos en lenguaje natural, para lo que desarrolha aplicaciones informáticas" (tradução nossa).
} 
O Vocabulário dialetal do Centro-Oeste (VDCO) foi desenvolvido em 2018 como tese de doutorado defendida na Universidade Estadual de Londrina (COSTA, 2018). Ele utilizou como aporte teórico a Lexicografia e também se valeu dos preceitos da Dialetologia e da Geolinguística, base de seu corpus - em grande medida dados inéditos do Atlas Linguístico do Brasil, além de recorrer ao auxílio da Linguística de Corpus e da Linguística Computacional.

Foi escolhido o termo vocabulário e não dicionário tendo em vista que se trata “[...] de um dicionário particular, restrito a uma área geográfica” (PORTO DAPENA, 2002). Ademais "[...] o termo vocabulário designa convencionalmente um domínio do léxico que se presta a um inventário e a uma descrição", segundo o Dicionário de linguística (DUBOIS et al., 2006). Nesse sentido, o VDCO se caracteriza como um vocabulário por reunir um tipo de léxico parcelar da variedade brasileira do português em uso na região CentroOeste. E, por tratar de uma norma lexical contemporânea, é também sincrônico, descritivo e monolíngue. Ordena suas entradas a partir da ordem alfabética, é de cunho semasiológico e tem suporte impresso, com perspectiva futura de versão também eletrônica.

Filia-se ao Atlas Linguístico do Brasil (ALiB), que cedeu parte de sua base de dados para a composição do corpus do trabalho, como já mencionado, e também ao Dicionário Dialetal do Brasil (DDB), que ofereceu suporte teórico e metodológico para o projeto. $\mathrm{O}$ VDCO também contribuiu para ambos os projetos maiores: ao ALiB, auxiliando nas tarefas de revisão de transcrições de inquéritos e tratamento lexicográfico; ao DDB, propondo novas abordagens e alterações ao método inicial e fornecendo os dados geolinguísticos do Centro-Oeste já tratados lexicograficamente.

Tendo em vista a relação entre os trabalhos, desde o início do VDCO, foi buscado favorecer a consulta, a migração de dados e a extração da base para a composição do Dicionário Dialetal Brasileiro. Por isso, foram selecionadas ferramentas computacionais que facilitariam essa integração, como o programa Excel, da Microsoft, e o FLEx, da SIL, uma inovação em relação aos passos anteriores do DDB. Isso foi possível pelo estudo do aporte teórico da Linguística Computacional e também de programas computacionais, que exigiram ainda conhecimentos em Informática. Igualmente, a organização do corpus requereu estudos em Linguística de Corpus, uma vez que esta fornece subsídios metodológicos para o tratamento de corpora para as diversas disciplinas que com eles trabalhem, entendendo-os sob o viés empírico e considerando a linguagem como sistema probabilístico.

O Excel foi escolhido não somente pela praticidade na alimentação dos dados ou pelo fácil acesso ou tratamento que o aplicativo possibilita às informações nele armazenadas mas especialmente pela possiblidade de migração de dados oferecida, já que, se o VDCO integrará o DDB, deve também priorizar uma forma prática e segura de transferir seus dados posteriormente.

Também não utilizado ainda pelo Dicionário Dialetal Brasileiro, o FieldWorks Language Explorer (FLEx) é um programa desenvolvido pelo Summer Institute of Linguistic (SIL International) e se mostrou muito profícuo, pois gera automaticamente os 
verbetes e organiza o dicionário de acordo com parâmetros pré-estabelecidos pelo usuário, neste caso elegíveis a partir do construto teórico da Lexicografia.

O VDCO, além de respeitar princípios lexicográficos, também se norteou por preceitos da Dialetologia e da Geolinguística no que tange aos critérios de organização da macroestrutura $^{11}$, como seleção de entradas e tipos de verbetes, bem como aos elementos componentes da microestrutura ${ }^{12}$, como abonações e remissivas.

A questão das remissivas é um item de bastante relevância para o DDB, haja vista almejar-se "[...] um sistema de remissão bastante eficiente e complexo, capaz de dar conta das co-referências possíveis, incluindo-se aí o sistema de identificação isoglóssica de cada unidade lexical no espaço geolinguístico brasileiro" (GRUPO NÊMESIS, 2018, online). Tal importância justifica-se pelo fato de que, por se tratar de um dicionário dialetal, seu objetivo deve ser também o de demonstrar ao consulente possíveis isoglossas, identificadas a partir da variação linguística demonstrada pelo uso de uma unidade léxica em detrimento de outra em diferentes espaços geográficos - como no caso do VDCO, que documentou 'banducha' como designação para 'tiara' / 'diadema' apenas em Formosa (GO).

A abonação, por sua vez, é outra proposta do VDCO para o DDB, visto que o primeiro trabalho vinculado ao DDB não contemplava esse componente (NEIVA, 2017), que se entende relevante para uma obra de cunho dialetal. Isso porque, além de atestar o uso concreto do item lexical em causa, revela traços sociais, históricos e geográficos da realidade linguística que documenta, que influencia fortemente a norma lexical de seus falantes e valida o uso de diversas variantes lexicais.

Para ilustrar essa argumentação, mostra-se a seguir um verbete do VDCO:

mão de vaca (pata de vaca) a. Quem evita ao máximo gastar dinheiro. [Mais antigamente falava «mão de vaca» [MS115-8]] QSL138/ALiB: Como se chama a pessoa que não gosta de gastar seu dinheiro e, às vezes, até passa dificuldades para não gastar? MT; MS; GO. cf. muxiba; mesquinho; caxias; canguinhas; avarento; muquirana; ridico; unha de fome; mão mirrada; murrinha; amarrado; mão de égua; pãoduro; mão fechada; seguro; sovina; mão segura; vil; cainha; miserável; econômico; munheca.

Lê-se, pois, a estrutura dos verbetes no Vocabulário: inicia-se pelo lema - lexia selecionada como entrada e lematizada ${ }^{13}$ a partir de preceitos da Lexicologia -,

${ }_{11}$ Para Rey-Debove (1971, p. 21), a macroestrutura é “[...] l'ensemble des entrées ordonnées, toujours soumise à une lecture verticale partielle".

12 “[...] L'ensemble de informations ordonnées de chaque article, réalisant un programme d'information constant pour tous les articles, et qui se lisent horizontalement à la suite de l'entrée" (REY-DEBOVE, 1971, p. 21).

${ }^{13}$ A lematização das entradas respeitou a norma padrão escrita formal da variante brasileira do português. Entretanto, tendo em vista a complexidade e as dimensões do corpus tratado, que possibilitou o conhecimento de muitos traços linguísticos, inclusive alguns mais raros, como as hapax legomena, muitos itens lexicais promovidos a entradas requereram outras pesquisas para o processo de lematização, uma vez que muitos deles não estão dicionarizados. Assim, foram consultados, além de dicionários gerais de língua de diversas épocas, também obras de caráter etimológico, folclórico e mesmo fontes diversas, como 
acompanhado da ou das variantes morfofonêmicas; classificação gramatical; definição que segue a teoria lexicográfica e pode ser perifrástica (no caso de substantivos e adjetivos) ou explicativa (para verbos); abonação; bibliografia - a pergunta do Projeto ALiB que originou a resposta; a legenda dialetal e as remissivas.

Trata-se de um verbete completo, que traz as informações lexicográficas acerca da variante lexical mais recorrente para designar o referente em questão. Como já afirmado, esse critério seguiu as orientações da Geolinguística no que tange à produtividade, destacando em termos lexicográficos os itens léxicos mais frequentes no corpus a cada novo conceito.

Difere do verbete remissivo pelo fato de este não conter definição nem bibliografia e no caso da remissão - que no verbete completo indica todas as variantes lexicais relacionadas -, aponta-se apenas para a unidade léxica mais produtiva, entrada dos verbetes completos.

Isso pode ser visto no verbete remissivo "pão-duro"14:

pão-duro a. [Pode ser que tenha, mas a gente aqui sempre costuma chamá "pão-duro» [MT104-3]] MT; MS; GO. cf. mão de vaca.

O parâmetro de produtividade também foi utilizado como diferencial para eleger o verbete completo no caso de itens com o mesmo número de ocorrências. Nesses casos, para a escolha de qual deles encabeçaria um verbete completo, foram utilizados critérios geolinguísticos, primeiro considerando a distribuição diatópica e, nas situações em que isso ainda fosse equivalente entre duas ou mais unidades léxicas, o caráter social do registro. Dessa maneira, as entradas dos verbetes completos foram selecionadas a partir de sua documentação em mais localidades (diatopia). O segundo critério, adotado apenas caso o primeiro não fosse suficiente, regeu essa seleção a contar da pluralidade de perfis de informantes que mencionaram a referida lexia.

No que se refere à legenda dialetal, o VDCO propôs ao DDB uma estrutura puramente textual, contendo a sigla do Estado em que a lexia foi proferida e a informação do informante que a mencionou (a centena diz respeito à localidade e a unidade, posterior ao traço, ao falante entrevistado) ${ }^{15}$. Ela se apresenta de duas formas: no corpo do verbete, contendo apenas o Estado em que se documentou o item léxico; porém, para um estudo mais aprofundado, como conhecer detalhes do registro (sexo, idade, grau de escolaridade e localidade de residência do entrevistado), indica-se ao consulente ler o apêndice do VDCO, que traz esses dados:

publicações dialetais talvez sem muito viés científico e, em situações extremas, em que nenhuma busca anterior solucionou a grafia indicada para a lexia, recorreu-se ao levantamento de frequência na rede internacional de computadores (XATARA, 2008), selecionando-se aquela com maior recorrência na Web.

${ }^{14} \mathrm{Na}$ abonação, optou-se por respeitar a fala dos informantes, tendo em vista que, mesmo se ocupando da norma lexical, o VDCO pode fomentar outros estudos, de outros níveis linguísticos.

${ }^{15}$ Para maiores informações sobre a metodologia do Atlas Linguístico do Brasil, ver Cardoso et al. (2014). 


\section{canguinhas MT106-2; MT109-3}

Nota-se que 'canguinhas', uma variante de 'mão de vaca', foi proferida por matogrossenses de Poxoréu (MT106) e de Barra do Garças (MT109), uma mulher jovem (-2) e um senhor (-3), ambos com no máximo o Ensino Fundamental completo.

Dessa maneira, o VDCO apresenta-se como uma possibilidade de tratamento lexicográfico de dados geolinguísticos, posto que aplicou preceitos de Lexicografia ao manipular um corpus de mais de 23 mil ocorrências advindo do Atlas Linguístico do Brasil, proposto inicialmente para a elaboração de um atlas e não de dicionários.

Assim, entende-se que pode oferecer novos caminhos para o fazer lexicográfico, além de disseminar para outros públicos os resultados do Projeto ALiB, acrescidos ainda de informações semânticas, gramaticais e discursivas.

Pretendeu-se assim discutir neste tópico a aplicação de conceitos da Lexicografia no tratamento de dados geolinguísticos, de modo a ilustrar a discussão teórica inicial e as possibilidades de interfaces entre a Lexicografia, a Dialetologia e a Geolinguística, no caso do VDCO auxiliadas também pela Linguística de Corpus e pela Linguística Computacional.

\section{CONSIDERAÇÕES FINAIS}

A interface entre Lexicografia, Dialetologia e Geolinguística, discutida neste texto em termos teóricos e práticos, mostra-se extremamente relevante para a elaboração de obras lexicográficas, notadamente quanto ao conhecimento sobre a realização efetiva de unidades léxicas na norma linguística documentada, especialmente no que se refere a marcas de uso.

Neste caso, pode-se percebê-la aplicada ao tratamento de dados geolinguísticos documentados pelo Atlas Linguístico do Brasil e compilados para a organização do VDCO. Esse propósito, inclusive, norteou a concepção do DDB, projeto maior a que se filia o VDCO, qual seja:

Assegurar a difusão mais ampla do conhecimento da realidade linguística de uma nação, no que tange aos usos lexicais, de forma a atender, de maneira econômica e com maior amplitude, o acesso aos dados dialetais, por parte de seus supostos principais grupos de interesse ou público-alvo, isto é, os estudiosos da língua e da cultura e a população em geral. (MACHADO FILHO, 2010, p. 50)

Isso porque a impressão de atlas linguísticos, consideradas suas especificidades gráficas, é economicamente onerosa, além do fato de que o próprio formato dessas publicações, de modo a possibilitar a visualização das informações, torna também complexo o seu manuseio. Essas características físicas podem restringir a consulta a essas produções.

O tratamento lexicográfico desse conteúdo e sua disposição em dicionários, por sua vez, podem contribuir em grande medida para a divulgação desses dados. O VDCO, por exemplo, contempla mais de 23 mil ocorrências em 1.604 entradas e está disposto em 169 
páginas entre o vocabulário propriamente dito (84 páginas) e o apêndice (85 páginas), este que apresenta a legenda dialetal a ser consultada apenas por aqueles que almejam conhecer os detalhes da documentação das variantes lexicais.

Além disso, por disponibilizar informações gramaticais, semânticas e discursivas sobre as entradas, o VDCO congrega em seus verbetes dados relevantes para o entendimento das lexias, tanto no que diz respeito à sua utilização quanto no que se refere às suas características linguísticas. Dessa forma, além de contribuir para o acesso a dados geolinguísticos, acrescenta-lhes informações, favorecendo maior entendimento sobre a norma lexical do Centro-Oeste, revelada de forma inédita pelo Atlas Linguístico do Brasil.

Favorecendo ainda essa inter-relação, o VDCO promove uma consulta enriquecedora aos usuários ao apresentar em sua macroestrutura verbetes completos e remissivos, estes se referindo àqueles, que alçaram essa posição na estrutura do Vocabulário por terem como lemas as variantes lexicais mais produtivas para a nomeação de cada conceito contemplado, e cujos verbetes completos apresentam uma lista de todas as entradas a eles relacionados, de forma que a consulta fique completa e auxilie o entendimento do lema.

A elaboração do VDCO pode também contribuir para a disseminação dos resultados dos atlas linguísticos, que, neste caso, para além de auxiliar a investigação da existência de uma norma lexical regional particular do Centro-Oeste brasileiro, aventada a partir de trabalhos com base em recortes menores, demonstrou uma realidade linguística ainda mais diversa: uma norma lexical de fato regional, além de particularidades entre os estados, o que pode ser lido na consulta ao trabalho completo.

Sendo assim, espera-se que este texto fomente novas discussões acerca da interdisciplinaridade da Lexicografia, que em muito contribui para o desenvolvimento da disciplina e, por conseguinte, para o aprimoramento de produções lexicográficas, que poderão melhorar consideravelmente seus projetos a partir da consulta e utilização de fontes confiáveis, como as advindas da Dialetologia e da Geolinguística, libertando-se dos limites que a comprimem, como anunciara Alvar (1980).

\section{REFERÊNCIAS}

AHUMADA LARA, Ignacio. Estudios de lexicografia regional del español. Jaén: Universidad Nacional de Educación a Distancia, 2000.

AHUMADA LARA, Ignacio. Panorama de la lexicografía regional del español. Kañina, Revista Artes y Letras, XXXI (1), Universidade de Costa Rica, p. 101-115, 2007.

ALVAR, Manuel. Atlas Lingüístico y diccionarios. AIH. Actas VII. Centro Virtual Cervantes, p. 53-73, 1980.

ALVAR EZQUERRA, Manuel. Nebrija, autor de diccionarios. Cuadernos de Historia Moderna, n. 13, Madri, p. 199-209, 1992.

ANGLADA ARBOIX, Emília. Lexicografía, metalexicografía, diccionario, discurso. Sintagma, n. 3, p. 5-11, 1991. 
AZORÍN FERNÁNDEZ, Dolores. La lexicografía como disciplina lingüística. In: MEDINA GUERRA, Antonia Maria (Org.). Lexicografia española. Barcelona: Ariel, 2003, p. 31-52.

BERBER SARDINHA, Tony. Lingüística de corpus: histórico e problemática. D.E.L.T.A., v. 16, n. 2, p. 323-367, 2000.

BÍBLIA. Português. Bíblia sagrada. Edição Pastoral. Tradução de Ivo Storniolo e Euclides Martins Balancin. São Paulo: Paulus, 1990.

BIDERMAN, Maria Tereza de Camargo. Os dicionários na contemporaneidade: arquitetura, métodos e técnicas. In: OLIVEIRA, Ana Maria Pinto Pires de; ISQUERDO, Aparecida Negri. As ciências do léxico: lexicologia, lexicografia e terminologia. Campo Grande: Editora UFMS, 2001, p. 131-144.

BRANDÃO, Sílvia Figueiredo. A geografia linguística no Brasil. São Paulo: Ática, 1991.

CAMACHO NIÑO, Jesús. El léxico dialectal del habla de Jaén. In: AHUMADA, Ignacio (Org.). Metalexicografía variacional. Diccionarios de regionalismos y diccionarios de especialidad. Málaga: Universidade de Málaga, 2010, p. 61-75.

CARDOSO, Suzana Alice Marcelino. Reflexões sobre a dialectologia. In: ISQUERDO, Aparecida Negri (Org.). Estudos geolingüísticos e dialetais sobre o português. Campo Grande: Editora UFMS, 2008, p. 13-31.

CARDOSO, Suzana Alice Marcelino. Geolinguística: tradição e modernidade. São Paulo: Parábola, 2010.

CARDOSO, Suzana Alice Marcelino; FERREIRA, Carlota. O léxico rural: glossário, comentários. Salvador: Universidade Federal da Bahia, 2000.

CARDOSO, Suzana Alice Marcelino da Silva et al. Atlas linguístico do Brasil. v. 1. Londrina: EDUEL, 2014.

CHAMBERS, Jack. K.; TRUDGILL, Peter. La dialetología. Madrid: Visor Libros SL, 1994. COSERIU, Eugênio. A geografia lingüística. In: COSERIU, Eugênio (Org.). O homem e sua linguagem. Tradução de Carlos Alberto Fonseca e Mário Ferreira. Rio de Janeiro; São Paulo: Presença; USP, 1982, p. 79-116.

COSTA, Daniela de Souza Silva. Vocabulário dialetal do Centro-Oeste: interfaces entre a lexicografia e a dialetologia. 2018. 352 f. Tese (Doutorado em Estudos da Linguagem) Universidade Estadual de Londrina, Londrina, 2018.

DUBOIS, Jean et al. Dicionário de linguística. São Paulo: Cultrix, 2006.

DURAN, Magali Sanches. Lexicografia e linguística de corpus. In: MAGALHÃES, José Sueli de Magalhães; TRAVAGLIA, Luiz Carlos (Orgs.). Múltiplas perspectivas em linguística. Uberlândia: EDUFU, 2008, p. 1793-1800. Disponível em: http://www.filologia.org.br/ileel/artigos/artigo 058.pdf. Acesso em: 11 dez. 2018.

FERNÁNDEZ-SEVILLA, Julio. Problemas de lexicografía actual. Bogotá: Publicaciones del Instituto Caro y Cuervo. Series Minor, XIX, 1974.

GARCÍA MOUTON, Pilar. Dialectologia y geografía lingüística. In: ALVAR, Manuel (Org.). Manual de dialectologia hispânica. El español de España. Barcelona: Ariel, 2009, p. 6377. 
GRUPO NÊMESIS. Dicionário dialetal brasileiro. Disponível em: https://gruponemesis.ufba.br/projetos/dicion \%C3\%A1rio-dialetal-brasileiro. Acesso em: 18 out. 2018.

HAENSCH, Günter. Aspectos prácticos de la elaboración de diccionarios. In: HAENSCH, Günter et al. (Orgs.). La lexicografía. De la lexicografía teórica a la lexicografía práctica. Madri: Gredos S.A., 1982, p. 395-534.

HAENSCH, Günter; OMEÑACA, Carlos. Los diccionarios del español en el siglo XXI. Problemas actuales de la lexicografía, los distintos tipos de diccionarios: una guía para el usuário, bibliografía de publicaciones sobre lexicografía. $2^{a}$ ed. Salamanca: Ediciones Universidad de Salamanca, 2004.

ISQUERDO, Aparecida Negri. Léxico regional e léxico toponímico: interfaces linguísticas, históricas e culturais. In: ISQUERDO, Aparecida Negri; SEABRA, Maria Cândida (Orgs.). As ciências do léxico: lexicologia, lexicografia e terminologia. v. IV. Campo Grande: Ed. UFMS, 2012, p. 115-140.

LARA, Luís Fernando. O dicionário e suas disciplinas. In: ISQUERDO, Aparecida Negri; KRIEGER, Maria da Graça (Orgs.). As ciências do léxico. Lexicologia, lexicografia e terminologia. v. II. Campo Grande: Editora UFMS, 2004, p. 133-152.

MACHADO FILHO, Américo Venâncio Lopes. Um ponto de interseção para a dialectologia e a lexicografia: a proposição de um dicionário dialetal brasileiro com base nos dados do ALiB. Estudos Linguísticos e Literários, v. 41, Salvador, p. 49-70, 2010.

MACHADO FILHO, Américo Venâncio Lopes; NEIVA, Isamar. Questões de método para a composição do Dicionário dialetal brasileiro: os dados da Bahia em foco. In: MOTA, Jacyra Andrade; PAIM, Marcela Moura Torres; RIBEIRO, Silvana Soares Costa (Orgs.). Documentos 5: Projeto Atlas Linguístico do Brasil, avaliações e perspectivas. Salvador: Quarteto, 2015, p. 317-331.

MOTA, Jacyra Andrade; CARDOSO, Suzana Alice Marcelino. Para uma nova divisão dos estudos dialetais brasileiros. In: MOTA, Jacyra Andrade; CARDOSO, Suzana Alice Marcelino (Orgs.). Documentos 2: Projeto Atlas Linguístico do Brasil. Salvador: Quarteto, 2006, p. 15-26.

NEIVA, Isamar. Vocabulário dialetal baiano. 2017. v. 1. 270f. Tese de Doutorado (Programa de Pós-Graduação em Língua e Cultura). Universidade Federal da Bahia, Salvador, 2017. PÉREZ HERNÁNDEZ, Chantal; MORENO ORTIZ, Antonio. Lingüistica computacional y lingüistica de corpus. Potencialidades para la investigación textual. 2009. Disponível em: http://tecnolengua.uma.es/doc2/trea2009.pdf. Acesso em: 11 dez. 2018.

PICHARDO, Estéban. Diccionario provincial de voces cubanas. Madrid: Imprenta de la Real Marina, $1836 . \quad$ Disponível em: http://bvpb.mcu.es/es/consulta/registro.cmd?id=406222. Acesso em: 27 dez. 2018.

PORTO DAPENA, José-Álvaro. Manual de técnica lexicográfica. Madri: Arco Livros S.A., 2002.

REY-DEBOVE, Josette. Étude linguistique et sémiotique des diccionaires français contemporains. Paris: Mouton, 1971.

ROMANO, Valter Pereira. Balanço crítico da geolinguística brasileira a e proposição de uma divisão. Entretextos, v. 13, n. 2, Londrina, p. 203-242, jul./dez. 2013. 


\section{$\operatorname{Rim}$

SOUSA FERNÁNDEZ, Xulio. Entre el atlas lingüístico y el diccionario. Un diccionario de léxico tradicional a partir de los materiales del ALPI. In: AHUMADA, Ignacio (Org.). Metalexicografía variacional. Diccionarios de regionalismos y diccionarios de especialidad. Málaga: Universidade de Málaga, 2010, p. 237-256.

XATARA, Cláudia Maria. A web para um levantamento de freqüência. In: MAGALHÃES, José Sueli de; TRAVAGLIA, Luiz Carlos (Orgs.). Múltiplas perspectivas em Lingüistica. Uberlândia: EDUFU, 2008, p. 770-777. Disponível em: <http://www.filologia.org.br/ileel/artigos/artigo_398.pdf>. Acesso em: 26 out. 2018.

Recebido em: 28/02/2019

Aprovado em: 07/06/2019

Publicado em: 28/09/2019 